\title{
miR-374c-5p regulates PTTG1 and inhibits cell growth and metastasis in hepatocellular carcinoma by regulating epithelial-mesenchymal transition
}

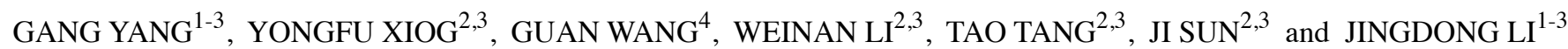 \\ ${ }^{1}$ First Clinical Medical College, Jinan University, Tianhe, Guangzhou, Guangdong 510632; \\ ${ }^{2}$ Department of Hepatobiliary Surgery, Affiliated Hospital of North Sichuan Medical College; \\ ${ }^{3}$ Institute of Hepato-Biliary-Pancreatic-Intestinal Disease, North Sichuan Medical College; \\ ${ }^{4}$ Physical Examination Center, Affiliated Hospital of North Sichuan Medical College, Nanchong, Sichuan 637000, P.R. China
}

Received October 12, 2021; Accepted February 15, 2022

DOI: $10.3892 / \mathrm{mmr} .2022 .12664$

\begin{abstract}
A large number of studies have reported that microRNA (miR)-374c-5p plays an important role in the occurrence and development of malignant tumors, but there is no research on the role of miR-374c-5p in hepatocellular carcinoma (HCC). The aim of the present study was to investigate the role of miR-374c-5p in HCC and the underlying molecular mechanism. The expression of miR-374c-5p in HCC tissues and HCC cell lines was analyzed via reverse transcription-quantitative PCR. The association between miR-374c-5p and clinical pathology was also analyzed in patients with HCC. Kaplan-Meier analysis and Cox multivariate analysis were used to evaluate the prognostic significance of miR-374c-5p in HCC. The biological functions of miR-374c-5p, including cell proliferation, migration and invasion and its potential molecular mechanism were analyzed in vivo and in vitro. In addition, the molecular mechanism of miR-374c-5p in HCC was further explored. The results demonstrated that miR-374c-5p expression was lower in HCC than in matched adjacent tissue samples. Patients with low expression of miR-374c-5p had poor prognosis and short survival time. Overexpression of miR-374c-5p inhibited HCC cell proliferation, migration and invasion in vitro. In vivo, it was found that overexpression of miR-374c-5p significantly inhibited the growth and proliferation of HCC cells. Dual-luciferase reporter assays verified that miR-374c-5p directly targets the 3'-untranslated region of pituitary tumor-transforming 1 (PTTG1) and regulates PTTG1 expression. In general, it was revealed that miR-374c-5p
\end{abstract}

Correspondence to: Dr Jingdong Li, First Clinical Medical College, Jinan University, 601 Huangpu Avenue West Road, Tianhe, Guangzhou, Guangdong 510632, P.R. China

E-mail: li-Jingdong@hotmail.com

Key words: microRNA-374c-5p, pituitary tumor-transforming 1, cell growth and metastasis, hepatocellular carcinoma, epithelialmesenchymal transition regulates the malignant biological behavior of HCC through PTTG1, thereby affecting epithelial-mesenchymal transition. Thus, miR-374c-5p is a potential biological indicator to predict poor prognosis in patients with HCC.

\section{Introduction}

Hepatocellular carcinoma (HCC) is a common malignant tumor (1). HCC occurrence is closely related to fibrosis and liver cirrhosis, which are mainly caused by nonalcoholic fatty liver, drinking or viral infection. After repeated exposure to risk factors, the liver experiences a series of changes in cell proliferation and abnormal proliferation and finally develops a malignant phenotype forming $\mathrm{HCC}(1,2)$. High metastasis is an important biological characteristic of HCC (1). With the continuous improvement in treatment methods, the survival period of patients has been improved to a certain degree. However, tumor invasion, metastasis and postoperative recurrence are the main causes of mortality of patients with HCC and exert substantial pressure and burden on patients and their families (2). Therefore, in-depth study of the mechanism of HCC metastasis and recurrence is very important for the treatment of HCC.

The invasion and metastasis of HCC are closely related to the signaling pathways that regulate the malignant development of tumors (3). Dysfunction of microRNAs (miRNAs) in HCC cells initiates the related signaling pathways that promote tumor invasion and metastasis (4). When miRNA is loaded into an RNA-induced silencing complex (RISC), the miRNA recognizes a binding in the target gene mRNA 3'-untranslated region (UTR) through its seed sequence (nucleotides 2-8 from the 5 ' end) and thus, RISC plays a role in the regulation of gene expression (5). There are three main effects of miRNAs: Transcription inhibition, mRNA cleavage or degradation (6). The function of miRNAs mainly relies on the aforementioned methods to inhibit downstream gene expression and weaken or eliminate the function of downstream genes (7). Studies have shown that the function of a signaling pathway is mainly exerted by effectors and miRNAs can change the expression of key effectors in a signaling pathway through the regulation 
of target genes, thereby affecting the normal function of the signaling pathway $(7,8)$. This type of intracellular miRNA regulation of target genes is very important for the function of tumor cell metastasis-related signaling pathways and its mechanism is worthy of in-depth study.

A previous study has demonstrated that miR-374c-5p is widely involved in the malignant biological behavior of tumors and plays an important role in tumor invasion and metastasis (9). There are few studies on miR-374c-5p with regard to tumors; while a few studies have reported its biological function, a lack of in-depth research remains on its specific mechanism, particularly in HCC. Its role in HCC remains unknown. The present study aimed to clarify the biological role of miR-374c-5p in HCC and to analyze its specific mechanism. The results of the present study provided a scientific and objective basis for understanding the mechanism of miR-374c-5p in HCC.

\section{Materials and methods}

Tissue samples and related clinical data. HCC tissue samples and matched normal adjacent tissue samples from 100 patients were collected between May 2014 and November 2016 at the Department of Hepatobiliary Surgery, Affiliated Hospital of North Sichuan Medical College (Nanchong, China), and during surgical treatment (the etiology of HCC cases in the present study is HBV, HCV and alcohol). The present study was performed in accordance with the principles outlined in the Declaration of Helsinki. The study was approved (approval no. 2014032) by the Human Trial Ethics Committee of the Affiliated Hospital of North Sichuan Medical College (Nanchong, China). Written informed consent was obtained from the patients who provided the specimens. Each tumor tissue sample was snap-frozen in liquid nitrogen and then stored at $-80^{\circ} \mathrm{C}$.

The detailed inclusion criteria were as follows: i) HCC was confirmed by postoperative pathology and the histopathological diagnosis was clear. Clinicopathological staging was performed according to the 7th edition of tumor node metastasis (TNM staging) system developed by the International Anticancer Alliance and the American Cancer Society; ii) patients were diagnosed with HCC for the first time without distant metastasis; iii) patients had not received any treatment before surgery; iv) complete follow-up information; v) no other serious self-malignant disease; and vi) with clinical, pathological and surgical data.

The exclusion criteria were as follows: i) Those who could not communicate normally; ii) patients with organic dysfunction of the heart, brain, lung or kidney; iii) patients who were diagnosed with HCC for the first time with distant metastasis; iv) patients with incomplete clinical and pathological data; v) patients with systemic diseases; and vi) patients with autoimmune dysfunction.

Cell culture and transfection. HCC cell lines Huh-7 (cat. no. 1101HUM-PUMC000679), MHCC-97H (cat. no. 4201PAT-CCTCC00404), MHCC-97L (cat. no. CL-0497), Hep3B (cat. no. HB-8064) and normal hepatocyte THLE-2 (cat. no. CRL-2706) were purchased from the American Type Culture Collection, Cell bank of China Typical Culture
Preservation Center (cat. no. MHCC-97H), Cell Resource Center, Institute of Basic Medicine, Chinese Academy of Medical Sciences (cat. no. Huh-7) and Procell Life Science \& Technology Co., Ltd. (cat. no. MHCC-97L) and cultured in high-glucose DMEM (Gibco; Thermo Fisher Scientific, Inc.) containing $10 \%$ fetal bovine serum (FBS) (Gibco; Thermo Fisher Scientific, Inc.) and 1\% cyanidin/streptomycin double antibiotic at $37^{\circ} \mathrm{C}$ and $5 \% \mathrm{CO}_{2}$.

miR-374c-5p mimic, miRNA negative control mimic (miR-NC), pre-miR-374c-5p, control lentivirus were purchased from Shanghai GeneChem, Inc. The lentivirus-mediated pre-miR-374c-5p in Huh-7 was performed according to the manufacturer's protocol: $4 \mu \mathrm{l}$ of lentivirus titer $\left(1 \times 10^{8} \mathrm{TU} / \mathrm{ml}\right)$ with pre-miR-374c-5p was added to $1 \times 10^{6} \mathrm{Huh}-7$ cells at $37^{\circ} \mathrm{C}$ for $12 \mathrm{~h}$ and three infection gradients (MOI=10, MOI=20, MOI=30). Then, the cells were cultured in DMEM supplemented with $10 \% \mathrm{FBS}, 1 \%$ penicillin-streptomycin and $0.5 \mu \mathrm{g} / \mathrm{ml}$ puromycin to obtain stable cell lines). miR-374c-5p inhibitor, miRNA-NC inhibitor, PTTG1 overexpression plasmid (pcDNA3.1-PTTG1) and empty pcDNA3.1 plasmid were designed and synthesized by Shanghai GenePharma Co., Ltd. The sequences were as follows: miR-374c-5p mimics, 5'-AUAAUACAACCUGCUAAGUGCU-3'; miR-NC, 5'-UUC UCCGAACGUGUCACGUTT-3'; miR-374c-5p inhibitor, 5'-AGCACUUAGCAGGUUGUAUUAU-3'; and NC-inhibitor, 5'-CAGUACUUUUGUGUAGUACAA-3'. HCC cells were seeded into six-well plates $\left(2 \times 10^{5}\right.$ cells/well $)$ and allowed to settle overnight prior to transfection. miR-NC (50 $\mathrm{nM})$ or miR-374c-5p mimics (50 nM) or miR-374c-5p inhibitors $(50 \mathrm{nM})$ were transfected for $48 \mathrm{~h}$ at $37^{\circ} \mathrm{C}$ and Lipofectamine ${ }^{\circledR}$ 3000 (Thermo Fisher Scientific, Inc.) was used for transient transfection. Cells were screened with $2 \mu \mathrm{g} / \mathrm{ml}$ puromycin. The duration of each screening was $48 \mathrm{~h}$ at $37^{\circ} \mathrm{C}$ and was repeated 2 times. Then, cells were harvested for subsequent reverse transcription-quantitative PCR (RT-qPCR) and western blot analysis.

$R T-q P C R$. Total RNA including miRNAs was extracted from HCC tissues, matched normal adjacent tissue and cell lines using miRNeasy Mini kit (Qiagen China Co., Ltd.) according to the manufacturer's protocol. Reverse transcription of cDNA was performed using PrimeScript RT Reagent kit (Takara Bio, Inc.) according to the manufacturer's protocol. In addition, qPCR was performed with SYBR Premix Ex Taq II (Takara Bio, Inc.) and a Light Cycler system (Roche Diagnostics $\mathrm{GmbH})$. The following thermocycling conditions for qPCR were used: Initial denaturation at $97^{\circ} \mathrm{C}$ for $10 \mathrm{~min}$; and 40 cycles of denaturation at $92^{\circ} \mathrm{C}$ for $20 \mathrm{sec}$, annealing at $58^{\circ} \mathrm{C}$ for $15 \mathrm{sec}$, and extension at $75^{\circ} \mathrm{C}$ for $15 \mathrm{sec}$. The results were analyzed using the $2^{-\Delta \Delta \mathrm{Cq}}$ method (10). The experiment was repeated three times to verify the authenticity of the experimental results (each sample was independently tested three times to verify the experimental results). U6 was used as an internal control for microRNA, and GAPDH was used for mRNA. Primers were designed using Vazyme miRNA software (v1.01) (Vazyme Biotech Co., Ltd.). The primers were as follows: miR-374c-5p RT primer, 5'-GTCGTATCG ACTGCAGGGTCCGAGGTATTCGCAGTCGATACGACA GCACT-3'; miR-374c-5p forward, 5'-ATAATACAACCT GCTAAGTGC-3' and reverse, 5'-ACTGCAGGGTCCGAG 
GTATT-3'; U6 forward, 5'-CTCGCTTCGGCAGCACAT ATACT-3' and reverse, 5'-ACGCTTCACGAATTTGCGTGT C-3'; and GAPDH forward, 5'-GGGTGGTGCAAAGAGAGT CA-3' and reverse, 5'-GCAGGAGGCATTGCTTACAAC-3'.

Western blotting. Total protein from HCC tissues, matched normal adjacent tissue and cell lines $\left(1 \times 10^{6}\right.$ cells/well) was extracted using RIPA lysis buffer (Beyotime Institute of Biotechnology). Protein was quantified using a Bradford protein assay (Bio-Rad Laboratories, Inc.) and a Nanodrop spectrophotometer. An equal amount $(25 \mu \mathrm{g})$ of protein was added to each well of $10 \%$ gels and resolved via SDS-PAGE. Proteins were transferred to PVDF membranes and were blocked by incubation for $1 \mathrm{~h}$ at $37^{\circ} \mathrm{C}$ with $5 \%$ non-fat powdered milk. The proteins on PVDF membranes were incubated with the following primary antibodies: PTTG1 (1:1,000; product code ab26273), N-cadherin (1:5,000; product code ab76011), vimentin (1:2,000; product code ab92547), Ki-67 (1:5,000; product code ab16667), E-cadherin (1:10,000; product code ab1416) and GAPDH (1:5,000; product code ab8245; all from Abcam) overnight at $4^{\circ} \mathrm{C}$. Then, the membranes were incubated with the appropriate HRP-conjugated secondary antibodies (1:5,000; cat. no. ab6721; Abcam and 1:5,000; cat. no. ab205719; Abcam) at room temperature for $1 \mathrm{~h}$. Finally, immunoreactive protein bands were visualized using an enhanced chemiluminescence solution (MilliporeSigma) and a ChemiDoc Imaging system (Bio-Rad Laboratories, Inc.). Protein expression was semi-quantified using Quantity One version 4.6 software (Bio-Rad Laboratories, Inc.).

Immunohistochemistry. The sample was fixed in $10 \%$ formalin for $12 \mathrm{~h}$ at room temperature. The sample $(4 \mu \mathrm{m})$ was dehydrated with xylene and a descending series of ethanol solutions $(100,100,95$ and $80 \%)$. Antigen retrieval was performed in $10 \mathrm{mmol} / \mathrm{l}$ sodium citrate solution $(\mathrm{pH} 6)$ at $100^{\circ} \mathrm{C}$ for $15 \mathrm{~min}$ and the samples were cooled for $30 \mathrm{~min}$. All slides were incubated with 5\% goat serum (OriGene Technologies, Inc.) for $15 \mathrm{~min}$ at room temperature to block non-specific binding at room temperature. The slides were incubated with antibodies against Ki-67 (1:500; product code ab92742; Abcam) at $4^{\circ} \mathrm{C}$ overnight. Subsequently, the samples were incubated with biotinylated secondary antibody (1:100; cat. no. SAP-9100; OriGene Technologies, Inc.) at $37^{\circ} \mathrm{C}$ for $30 \mathrm{~min}$ then stained with 3,3-diaminobenzidine (DAB; cat. no. K5007; Dako; Agilent Technologies, Inc.) at room temperature for $10 \mathrm{sec}$ and Mayer's hematoxylin. The membranes were then washed with phosphate-buffered saline (PBS) and stained with DAB for $30 \mathrm{sec}$ at room temperature. Slides were visualized using a light microscope (magnification, $\mathrm{x} 400$; Zeiss AG).

miRNA prediction. TargetScan (version 7.1; http://www. targetscan.org), Oncomir (http://www.oncomir.org/) and miRWalk (http://mirwalk.umm.uni-heidelberg.de/), were used to predict target genes and conserved sites bound by miR-374c-5p.

Luciferase reporter assay. TargetScan was used to identify downstream target genes of miR-374c-5p. The wild-type (WT) PTTG1 3'-UTR and mutant (MUT) PTTG1 3'-UTR oligonucleotides containing the putative binding site for
miR-374c-5p were cloned into the firefly luciferase-expressing pMIR-REPORT vector (Obio Technology Corp., Ltd.). These constructs were co-transfected using Lipofectamine ${ }^{\circledR} 3000$ (Thermo Fisher Scientific, Inc.) with miR-374c-5p mimics, miR-NC mimics, miR-374c-5p inhibitor and miRNA-NC inhibitor into Huh-7 cells. After $48 \mathrm{~h}$ of transfection, luciferase activity was determined using a Dual-Luciferase Reporter Assay kit (Promega Corporation) according to the manufacturer's protocol. The ratio of Renilla luciferase activity to firefly luciferase activity was calculated. The firefly luciferase activity was normalized to the Renilla luciferase activity.

Cell Counting Kit 8 (CCK-8). Huh-7 and Hep3B cells were seeded into 96 -well plates $\left(1 \times 10^{3}\right.$ cells/well $)$ and incubated at $37^{\circ} \mathrm{C}$ for 24,48 or $72 \mathrm{~h}$. Then, CCK-8 reagent $(10 \mu \mathrm{l}$; Dojindo Molecular Technologies, Inc.) was added to each well and plates were incubated at $37^{\circ} \mathrm{C}$ for $2 \mathrm{~h}$. The absorbance was measured at $450 \mathrm{~nm}$ by a spectrophotometer (Bio-Rad Laboratories, Inc.).

5-Ethynyl-2'-deoxyuridine (EdU) assay. Huh-7 and Hep3B cells were seeded into 96 -well plates $\left(2.5 \times 10^{4}\right.$ cells/well $)$ and incubated at $37^{\circ} \mathrm{C}$ until the cells reached $30 \%$ confluence. Next, the cells were incubated with $\operatorname{EdU}(50 \mu \mathrm{M})$ for $2 \mathrm{~h}$, 0.5\% Triton X-100 and ApolloR reaction cocktail (100 $\mu \mathrm{l})$ for $30 \mathrm{~min}$ and $100 \mu 1$ Hoechst 33342 for $30 \mathrm{~min}$, sequentially. Cell proliferation was analyzed by assessing the percentage of EdU-positive cells in all cells in each sample using a fluorescence microscope (Lionheart; BioTek Instruments, Inc.; magnification, x100) and ImageJ software (version 1.8.0; National Institutes of Health) was used for cell counting.

Wound healing assay. Cell migration was examined using wound healing assays. Briefly, Huh-7 and Hep3B cells $\left(5 \times 10^{5}\right.$ cells/well) were cultured in six-well plates. When the cells reached confluence (90-100\%), any non-adherent cells were washed away with PBS. The cell monolayer was scratched with a pipette tip $(10 \mu \mathrm{l})$ to generate 3 scratch wounds and then rinsed with PBS to remove non-adherent cells, and the medium was replaced with fresh DMEM high glucose medium without FBS. After 0 and $48 \mathrm{~h}$, the distance between the wound edges was measured. The wells were imaged using an inverted microscope (Olympus Corporation) at x100 magnification. ImageJ v1.8.0 (National Institutes of Health) software was used for analysis.

Matrigel invasion assays. For the invasion assay, Huh-7 and Hep3B cells were resuspended in high-glucose DMEM containing 1\% FBS and seeded into the upper Transwell chamber at a density of $1 \times 10^{5}$ cells/well. Transwell inserts ( $8 \mu \mathrm{m}$ pore size) (Corning, Inc.) were precoated with Matrigel $(1 \mathrm{mg} / \mathrm{ml})$ at $37^{\circ} \mathrm{C}$ for $30 \mathrm{~min}$. A total of $500 \mu \mathrm{l}$ of high-glucose DMEM containing 10\% FBS was added to the matched lower chamber. After $36 \mathrm{~h}$ of incubation, the Transwell chambers were fixed with $4 \%$ paraformaldehyde at room temperature for $30 \mathrm{~min}$ and stained with $0.5 \%$ crystal violet at room temperature for $20 \mathrm{~min}$. The number of stained cells randomly selected from six fields was counted and images were captured under a light microscope (magnification, x200; Olympus Corporation). 

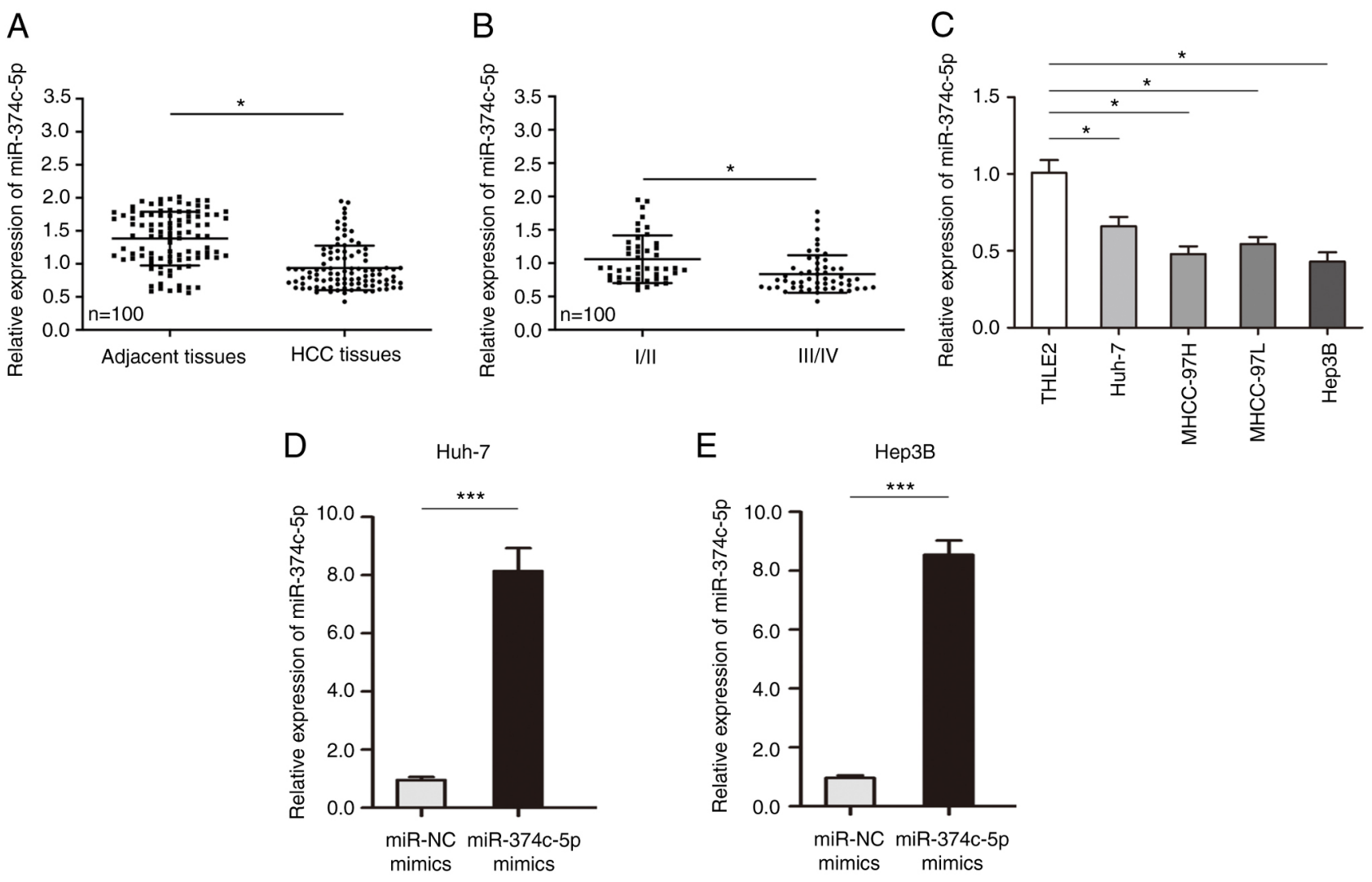

Figure 1. Expression of miR-374c-5p in HCC. (A) The expression of miR-374c-5p in HCC and matched adjacent tissues. (B) The expression of miR-374c-5p in HCC with different TNM grades. (C) The expression of miR-374c-5p in various HCC cell lines. (D) miR-374c-5p was overexpressed in Huh-7 cells. (E) miR-374c-5p was overexpressed in Hep3B cells. ${ }^{*} \mathrm{P}<0.05$ and ${ }^{* * *} \mathrm{P}<0.001$. miR, microRNA; HCC, hepatocellular carcinoma.

Flow cytometric analysis of cell apoptosis. Huh-7 and Hep3B cells $\left(1 \times 10^{5}\right.$ cells/well) were seeded into six-well plates. Once they reached confluence $(70-80 \%)$, the cells were collected (300 $\mathrm{x}$ g for $3 \mathrm{~min}$ at room temperature) and incubated with Annexin V-FITC $(5 \mu \mathrm{l})$ and propidium iodide solution (5 $\mu \mathrm{l}$; Biogot Technology Co., Ltd.) at room temperature for 15 min according to the manufacturer's instructions. Cells were subsequently suspended in $500 \mu \mathrm{l}$ binding buffer. Cell apoptosis progression was analyzed using flow cytometry (FACSAria; BD Biosciences). All data were analyzed with ModFit version 4.0 (Verity Software House, Inc.)

Tumorigenesis assay. The 5-week-old male BALB/c-nu mice (total number, $10 ; \mathrm{n}=5$ in each group; age, 5 weeks; weight, 20-25 g) were purchased from the Shanghai Experimental Animal Center (Shanghai, China) and were kept at the Animal Center of Affiliated Hospital of North Sichuan Medical College at $25^{\circ} \mathrm{C}$ and $40-70 \%$ humidity, with a 12 -h light/dark cycle and free access to food and water. All animal experiments were approved by the Animal Care Ethics Review Committee of Affiliated Hospital of North Sichuan Medical College, approval no 20201026) and the method of euthanasia was cervical dislocation (when the heart stopped completely, the mouse was determined as dead). Body weight loss $>20 \%$ was assumed to be a humane endpoint for euthanasia. For the in vivo tumor growth assay, $1 \times 10^{6}$ Huh-7 cells were resuspended with sterile PBS, infected with the pre-miR-374c-5p or control lentivirus and were subcutaneously injected into the flank of each nude mouse. Tumor sizes (the length and width of tumor nodules) were measured every 5 days. At 30 days post-injection, the mice were anaesthetized with pentobarbital sodium (100 mg/kg body weight) and sacrificed by cervical dislocation. The tumor volume calculation formula was as follows: Volume $=\left(\right.$ length $\mathrm{x}$ width $\left.{ }^{2}\right) / 2(11)$.

Statistical analyses. All quantitative data are presented as the mean \pm SD of at least three independent experiments. Statistical data were analyzed using SPSS version 20.0 software (IBM Corp.) and GraphPad Prism version 6.0 software (GraphPad Software, Inc.). Differences between groups were analyzed using unpaired Student's t-test or one-way ANOVA followed by Tukey's post hoc test. The Kaplan-Meier method was used to assess overall survival (OS) and disease-specific survival (DSS) and log-rank test was used to analyze differences between the curves. Associations between clinicopathological parameters and miR-374c-5p expression were analyzed using Pearson's chi-squared test. $\mathrm{P}<0.05$ was considered to indicate a statistically significant difference.

\section{Results}

miR-374c-5p expression is downregulated in HCC and related cells. First, the expression of miR-374c-5p in HCC was analyzed and the results revealed that the expression of miR-374c-5p in HCC was lower than in matched adjacent tissue samples (Fig. 1A; $\mathrm{P}<0.05$ ). The expression of miR-374c-5p was lower in patients with later stage $\mathrm{HCC}$ (Fig. 1B; P<0.05). In HCC cell lines, the expression of 
Table I. Associations between miR-374c-5p and clinicopathological features of patients with hepatocellular carcinoma.

\begin{tabular}{|c|c|c|c|c|}
\hline \multirow[b]{2}{*}{ Clinicopathological characteristics } & \multirow[b]{2}{*}{ Cases } & \multicolumn{2}{|c|}{ Expression level of miR-374c-5p } & \multirow[b]{2}{*}{ P-value } \\
\hline & & Low $(n=69)$ & High $(n=31)$ & \\
\hline Sex & & & & 0.875 \\
\hline Male & 56 & 39 & 17 & \\
\hline Female & 44 & 30 & 14 & \\
\hline Age, years & & & & 0.628 \\
\hline$<50$ & 48 & 32 & 16 & \\
\hline$\geq 50$ & 52 & 37 & 15 & \\
\hline $\mathrm{AFP}(\mathrm{ng} / \mathrm{ml})$ & & & & 0.728 \\
\hline$\leq 20$ & 38 & 27 & 11 & \\
\hline$>20$ & 62 & 42 & 20 & \\
\hline HBsAg & & & & 0.878 \\
\hline Positive & 72 & 50 & 22 & \\
\hline Negative & 28 & 19 & 9 & \\
\hline TNM stage & & & & 0.04 \\
\hline $\mathrm{I} / \mathrm{II}$ & 46 & 27 & 19 & \\
\hline III/IV & 54 & 42 & 12 & \\
\hline Tumor size (cm) & & & & 0.146 \\
\hline$\leq 5$ & 43 & 33 & 10 & \\
\hline$>5$ & 57 & 36 & 21 & \\
\hline Multiplicity & & & & 0.041 \\
\hline Single & 43 & 25 & 18 & \\
\hline Multiple ( $\geq 2)$ & 57 & 44 & 13 & \\
\hline Intrahepatic metastasis & & & & 0.935 \\
\hline Presence & 49 & 34 & 15 & \\
\hline Absence & 51 & 35 & 16 & \\
\hline Child-Pugh & & & & 0.621 \\
\hline A & 45 & 30 & 15 & \\
\hline $\mathrm{B}$ & 39 & 29 & 10 & \\
\hline $\mathrm{C}$ & 16 & 10 & 6 & \\
\hline
\end{tabular}

miR, microRNA; AFP, $\alpha$-fetoprotein; HBsAg, hepatitis B surface antigen; TNM, tumor, node, metastasis.

miR-374c-5p was significantly lower than that in normal liver cell line THLE-2 (Fig. $1 \mathrm{C} ; \mathrm{P}<0.05$ ). To evaluate whether miR-374c-5p is involved in the malignant biological behavior of HCC, two HCC cell lines (Huh-7 and Hep3B) were transfected with miR-374c-5p mimic and the expression level of miR-374c-5p in Huh-7 and Hep3B cells was successfully increased (Fig. 1D and $\mathrm{E} ; \mathrm{P}<0.001$ ).

miR-374c-5p is associated with poor prognosis in HCC. The average value of relative miR-374c-5p expression was used to divide the patients into 'high' or 'low' groups. miR-374c-5p expression was low in 69 out of $100 \mathrm{HCC}$ samples (69\%) and high in 31 out of $100 \mathrm{HCC}$ samples (31\%) and miR-374c-5p expression was positively associated to TNM stage $(\mathrm{P}=0.040)$ and multiplicity $(\mathrm{P}=0.041)$ and $\mathrm{miR}-374 \mathrm{c}-5 \mathrm{p}$ was not found to be associated with liver cirrhosis (Table I). Kaplan-Meier survival analysis revealed that HCC patients with low miR-374c-5p expression had significantly shorter OS than those with high miR-374c-5p expression in (Fig. $2 \mathrm{~A} ; \mathrm{P}=0.005$ ). Univariate analysis showed that TNM stage (HR, 1.361; $\mathrm{P}=0.021)$ and miR-374c-5p expression $(\mathrm{HR}, 1.336 ; \mathrm{P}=0.011)$ were significantly associated with OS in HCC (Table II). Multivariate analysis demonstrated that TNM stage (HR, 1.482; $\mathrm{P}=0.020)$ and miR-374c-5p expression (HR, 1.450; $\mathrm{P}=0.015)$ were independent prognostic factors for OS in HCC (Table II).

Kaplan-Meier survival analysis revealed that low miR-374c-5p expression had significantly shorter DSS than those with high miR-374c-5p expression (Fig. 2B; $\mathrm{P}=0.007$ ). Univariate analysis showed that TNM stage (HR, 1.421; $\mathrm{P}=0.011)$ and $\mathrm{miR}-374 \mathrm{c}-5 \mathrm{p}$ expression $(\mathrm{HR}, 1.033 ; \mathrm{P}=0.022)$ were significantly associated with DSS in HCC (Table III). Multivariate analysis revealed that TNM stage (HR, 1.506; $\mathrm{P}=0.015$ ) and miR-374c-5p expression (HR, 1.047; $\mathrm{P}=0.024)$ were independent prognostic factors for DSS in HCC (Table III). 

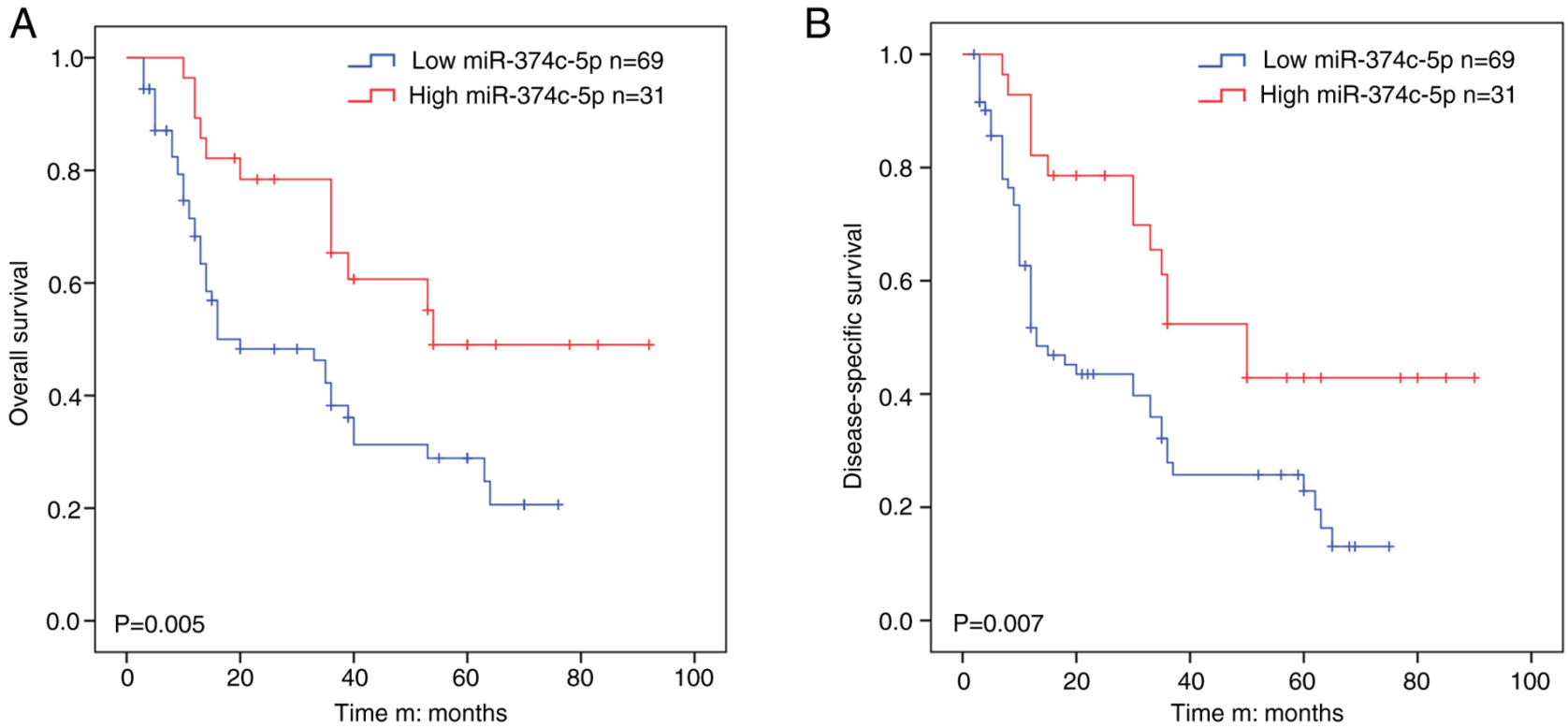

Figure 2. Association between miR-374c-5p and poor prognosis of patients with HCC. (A) Kaplan-Meier analysis of the overall survival of HCC patients with high and low miR-374c-5p expression. (B) Kaplan-Meier analysis of disease-specific survival between HCC patients with high and low miR-374c-5p expression. miR, microRNA; HCC, hepatocellular carcinoma.

Increasing the expression of miR-374c-5p inhibits the proliferation, invasion, migration and promotes the apoptosis of HCC in vitro. Cell proliferation ability was then assessed with CCK-8 assays and the results revealed that overexpression of miR-374c-5p significantly inhibited Huh-7 and Hep3B cell proliferation (Fig. $3 \mathrm{~A}$ and $\mathrm{B} ; \mathrm{P}<0.01$ ). The number of Huh-7 and Hep3B EdU-positive cells in the miR-374c-5p overexpression group was less than in the control group (Fig. 3C and D; $\mathrm{P}<0.01$ ). Furthermore, overexpression of miR-374c-5p significantly inhibited Huh-7 and Hep3B cell migration and invasion (Fig. 3E-H; P<0.05). In addition, transfection with miR-374c-5p mimics significantly promoted Huh-7 and Hep3B cell apoptosis (Fig. 3I and J; $\mathrm{P}<0.05)$.

PTTG1 is a direct target gene of miR-374c-5p in HCC. A total of 3 miRNA databases identified PTTG1 as a potential target of miR-374c-5p and the complementary sequence of miR-374c-5p was found in the 3'-UTR of PTTG1 mRNA (Fig. 4A). Luciferase reporter vectors containing the WT or MUT PTTG1 3'-UTR sequence were used to reveal the interaction of miR-374c-5p with PTTG1. The results demonstrated that co-transfection with miR-374c-5p mimics significantly inhibited luciferase activity in cells transfected with WT PTTG1 3'-UTR (Fig. 4B; P<0.05). Additionally, co-transfection with miR-374c-5p inhibitor significantly promoted luciferase activity in cells transfected with WT PTTG1 3'-UTR (Fig. 4C; P<0.05). Huh-7 and Hep3B cells were transfected with miR-374c-5p inhibitor and the expression level of miR-374c-5p was successfully decreased in Huh-7 and Hep3B (Fig. S1; P<0.05).

RT-qPCR and western blot assays revealed that miR-374c-5p overexpression significantly reduced PTTG1 mRNA and protein expression and inhibiting the expression of miR-374c-5p promoted PTTG1 mRNA and protein expression (Fig. 4D and $\mathrm{E} ; \mathrm{P}<0.05$ ).
PTTG1 abolishes the inhibitory effect of miR-374c-5p on HCC proliferation, migration, invasion and its promoting effect on apoptosis. To determine whether PTTG1 is a direct target gene of miR-374c-5p, a loss-of-function experiment was performed on pre-miR-374c-5p-Huh-7 and pre-miR-374c-5p-Hep3B cells. CCK-8 assays revealed that restoration of PTTG1 expression significantly abolished the inhibitory effects of miR-374c-5p on proliferation (Fig. 5A and $\mathrm{B} ; \mathrm{P}<0.05$ ). As demonstrated in Fig. 5C and D, restoration of PTTG1 expression significantly abolished the inhibitory effects of miR-374c-5p on EdU incorporation. Furthermore, restoration of PTTG1 expression significantly abolished the inhibitory effects of miR-374c-5p on migration and invasion (Fig. $5 \mathrm{E}-\mathrm{H} ; \mathrm{P}<0.05)$. In addition, restoration of PTTG1 expression significantly abolished the promotion of Huh-7 and Hep3B cell apoptosis (Fig. 5I and J; $\mathrm{P}<0.05)$.

Increasing the expression of $m i R-374 c-5 p$ significantly inhibits the proliferation of HCC in vitro. The influence of miR-374c-5p on proliferation in vivo was further identified; Huh-7 cells were stably transfected with miR-374c-5p overexpression vector and then injected into the flanks of nude mice to form subcutaneous ectopic tumors. Huh-7 cells were transfected with pre-miR-374c-5p and the expression level of miR-374c-5p was successfully increased in Huh-7 cells (Fig. S2; $\mathrm{P}<0.001$ ). As revealed in Fig. 6A-C, increasing the expression of miR-374c-5p significantly decreased the tumor volume and weight $(\mathrm{P}<0.05)$. In addition, increasing the expression of miR-374c-5p significantly inhibited the expression of Ki-67 in tumor tissues (Fig. 6D; $\mathrm{P}<0.05$ ).

miR-374c-5p regulates epithelial-mesenchymal transition (EMT) through PTTG1. After restoring the expression of PTTG1, the expression of N-cadherin, vimentin and Ki-67 was restored to a certain extent. The expression of E-cadherin, was inhibited to a certain extent (Fig. 7; $\mathrm{P}<0.05$ ). 
Table II. Univariate and multivariate analysis of different prognostic variables influencing overall survival in patients with hepatocellular carcinoma.

\begin{tabular}{|c|c|c|c|c|c|}
\hline \multirow[b]{2}{*}{ Clinicopathological characteristics } & \multirow[b]{2}{*}{$\mathrm{n}$} & \multicolumn{2}{|c|}{ Univariate analysis } & \multicolumn{2}{|c|}{ Multivariate analysis model } \\
\hline & & $\operatorname{HR}(95 \% \mathrm{CI})$ & P-value & $\mathrm{HR}(95 \% \mathrm{CI})$ & P-value \\
\hline Sex & & $0.63(0.563-1.398)$ & 0.607 & & \\
\hline Male & 56 & & & & \\
\hline Female & 44 & & & & \\
\hline Age, years & & $0.73(0.483-1.032)$ & 0.481 & & \\
\hline$<50$ & 48 & & & & \\
\hline$\geq 50$ & 52 & & & & \\
\hline $\operatorname{AFP}(\mathrm{ng} / \mathrm{ml})$ & & $1.203(1.318-3.601)$ & 0.63 & & \\
\hline$\leq 20$ & 38 & & & & \\
\hline$>20$ & 62 & & & & \\
\hline HBsAg & & $1.218(1.003-2.984)$ & 0.505 & & \\
\hline Positive & 72 & & & & \\
\hline Negative & 28 & & & & \\
\hline TNM stage & & $1.361(0.946-2.036)$ & 0.021 & $1.482(1.003-3.458)$ & 0.02 \\
\hline $\mathrm{I} / \mathrm{II}$ & 46 & & & & \\
\hline III/IV & 54 & & & & \\
\hline \multicolumn{6}{|l|}{ Tumor size (cm) } \\
\hline$\leq 5$ & 43 & & & & \\
\hline$>5$ & 57 & & & & \\
\hline Multiplicity & & $0.609(0.637-1.669)$ & 0.463 & & \\
\hline Single & 43 & & & & \\
\hline Multiple ( $\geq 2)$ & 57 & & & & \\
\hline Intrahepatic metastasis & & $0.366(0.691-1.238)$ & 0.556 & & \\
\hline Presence & 49 & & & & \\
\hline Absence & 51 & & & & \\
\hline Child-Pugh & & $0.861(0.567-1.3309)$ & 0.433 & & \\
\hline A & 45 & & & & \\
\hline $\mathrm{B}$ & 39 & & & & \\
\hline $\mathrm{C}$ & 16 & & & & \\
\hline miR-374c-5p expression & & $1.336(0.894-1.739)$ & 0.011 & $1.45(0.963-2.003)$ & 0.015 \\
\hline Low & 69 & & & & \\
\hline High & 31 & & & & \\
\hline
\end{tabular}

HR, hazard ratio; CI, confidence interval; AFP, $\alpha$-fetoprotein; HBsAg, hepatitis B surface antigen; TNM, tumor, node, metastasis; miR, microRNA.

\section{Discussion}

Cancer is a complex disease involving multiple genes and pathways (12). Therefore, cancer treatment targeting a single gene is not very useful. One miRNA can regulate the expression of hundreds of genes involved in different cell functions, making miRNA a promising therapeutic target (13). Since the first report of the abnormal regulation of miRNAs in cancer in 2002 (14), numerous studies have found that miRNAs play a critical role in tumorigenesis, including tumor suppressor miRNAs (ts-miRs) and oncogene miRNAs (onco-miRs) $(14,15)$. Upregulated onco-miRs and downregulated ts-miRNAs lead to the occurrence and development of tumors (15). These miRNAs have attracted widespread attention as biomarkers and therapeutic targets.

miRNAs are small noncoding RNAs involved in the regulation of gene expression and currently there are 1,917 human genome miRNA entries (16). The biosynthesis of miRNAs is a rapid process. Studies on Drosophila have shown that the biosynthesis of miRNAs is the fastest among transcripts $(16,17)$. Similar to genes encoding proteins, miRNAs may have independent transcriptional regulatory units, but they are often located within introns of host genes, suggesting coregulation of transcription (18). However, the expression of miRNAs is not necessarily related to the level of their host genes. Compared with their host genes, numerous 
Table III. Univariate and multivariate analysis of different prognostic variables influencing disease-specific survival in patients with hepatocellular carcinoma.

\begin{tabular}{|c|c|c|c|c|c|}
\hline \multirow[b]{2}{*}{ Clinicopathological characteristics } & \multirow[b]{2}{*}{$\mathrm{n}$} & \multicolumn{2}{|c|}{ Univariate analysis } & \multicolumn{2}{|c|}{ Multivariate analysis model } \\
\hline & & HR $(95 \% \mathrm{CI})$ & P-value & HR $(95 \% \mathrm{CI})$ & P-value \\
\hline Sex & & $0.438(0.601-1.266)$ & 0.552 & & \\
\hline Male & 56 & & & & \\
\hline Female & 44 & & & & \\
\hline Age, years & & $0.579(0.683-1.531)$ & 0.773 & & \\
\hline$<50$ & 48 & & & & \\
\hline$\geq 50$ & 52 & & & & \\
\hline $\operatorname{AFP}(\mathrm{ng} / \mathrm{ml})$ & & $1.396(1.435-3.669)$ & 0.707 & & \\
\hline$\leq 20$ & 38 & & & & \\
\hline$>20$ & 62 & & & & \\
\hline HBsAg & & $1.007(1.047-3.607)$ & 0.633 & & \\
\hline Positive & 72 & & & & \\
\hline Negative & 28 & & & & \\
\hline TNM stage & & $1.421(0.681-2.614)$ & 0.011 & $1.506(0.763-2.964)$ & 0.015 \\
\hline $\mathrm{I} / \mathrm{II}$ & 46 & & & & \\
\hline III/IV & 54 & & & & \\
\hline Tumor size $(\mathrm{cm})$ & & & & & \\
\hline$\leq 5$ & 43 & & & & \\
\hline$>5$ & 57 & & & & \\
\hline Multiplicity & & $1.223(0.537-1.336)$ & 0.72 & & \\
\hline Single & 43 & & & & \\
\hline Multiple ( $\geq 2)$ & 57 & & & & \\
\hline Intrahepatic metastasis & & $0.743(0.631-1.576)$ & 0.607 & & \\
\hline Presence & 49 & & & & \\
\hline Absence & 51 & & & & \\
\hline Child-Pugh & & $0.438(0.364-1.483)$ & & & \\
\hline A & 45 & & & & \\
\hline B & 39 & & & & \\
\hline $\mathrm{C}$ & 16 & & & & \\
\hline miR-374c-5p expression & & $1.033(0.537-1.209)$ & 0.022 & $1.047(0.673-1.557)$ & 0.024 \\
\hline Low & 69 & & & & \\
\hline High & 31 & & & & \\
\hline
\end{tabular}

HR, hazard ratio; CI, confidence interval; AFP, $\alpha$-fetoprotein; HBsAg, hepatitis B surface antigen; TNM, tumor, node, metastasis; miR, microRNA.

intronic miRNAs have independent transcription start sites and are controlled by different promoters and/or other regulatory sequences (19). For example, super-enhancers involved in cell characteristics can drive both the transcription and processing of miRNAs (20). Interestingly, super-enhancers are also dysregulated in human cancers, and may at least partially explain the abnormal expression of certain oncogenic miRNAs (20).

miR-374c-5p has been reported to be involved in the malignant progression of a variety of tumors. For example, the expression of miR-374c-5p was significantly low in cervical cancer and increasing miR-374c-5p expression significantly improved the invasion and migration abilities of cervical cancer cells (21). In addition, miR-374c-5p inhibited Snail by directly targeting FOXC1 and inhibiting FOXC1 expression (21). In breast cancer, low miR-374c-5p expression promoted the proliferation, migration and EMT of breast cancer cells (22). MiR-374c-5p interacted with TAF7 and downregulated its expression (22). In addition, miR-374c-5p regulated DEP domain containing 1 (DEPDC1) by mediating TAF7. Finally, miR-374c-5p inhibited breast cancer development through TAF7-mediated DEPDC1 transcriptional regulation (22). Based on literature analysis, it was found that miR-374c-5p can significantly regulate downstream target genes and related signaling pathways in HCC and regulate the malignant progression of $\mathrm{HCC}$ by affecting factors related to 
A

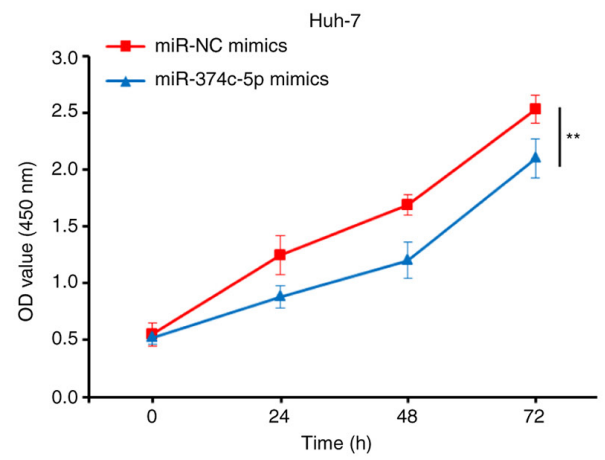

C
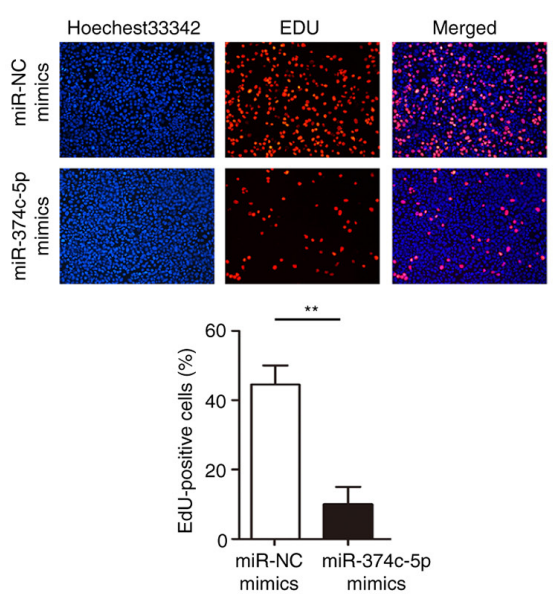

E
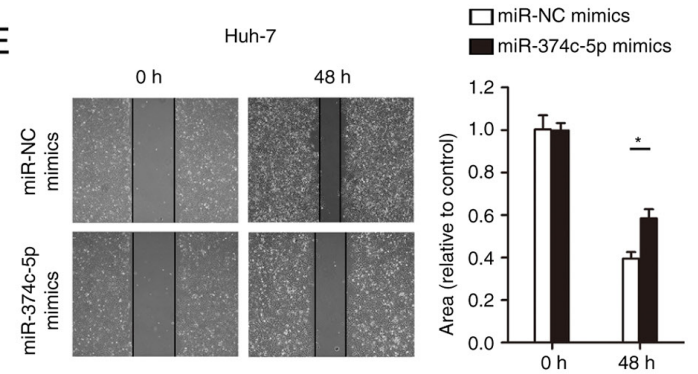

G
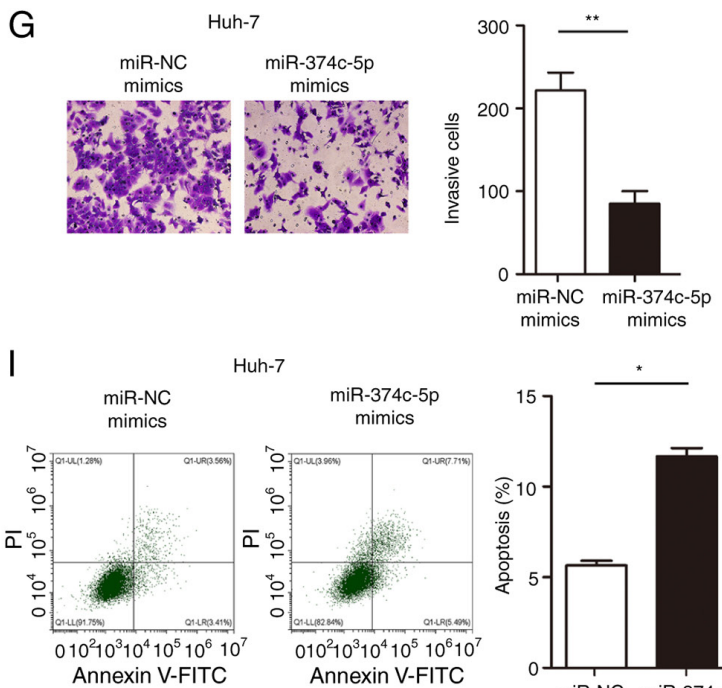

Huh-7
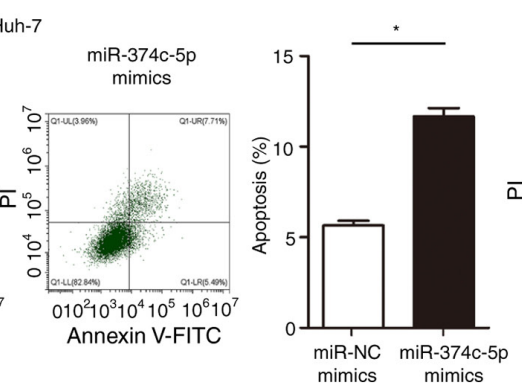

B
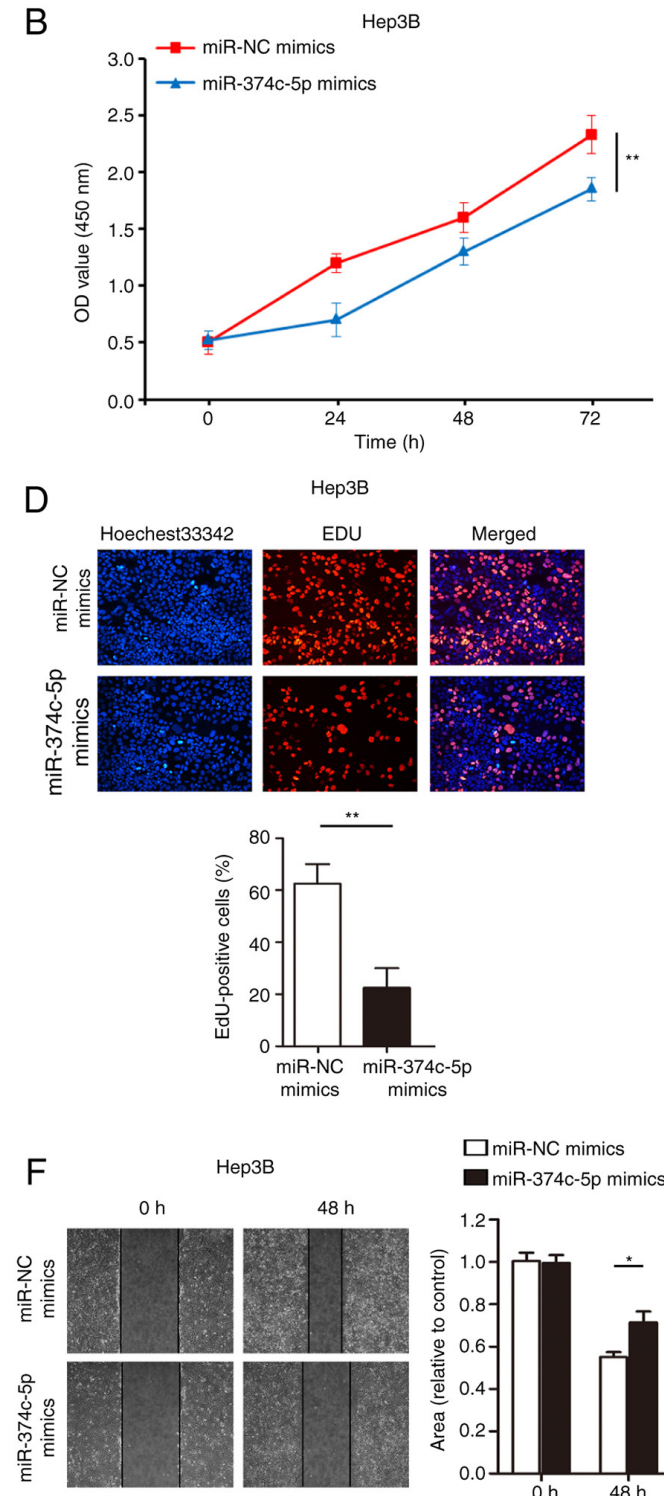

Нер3В

$\square$ miR-NC mimics

miR-374c-5p mimics

$\mathrm{H}$
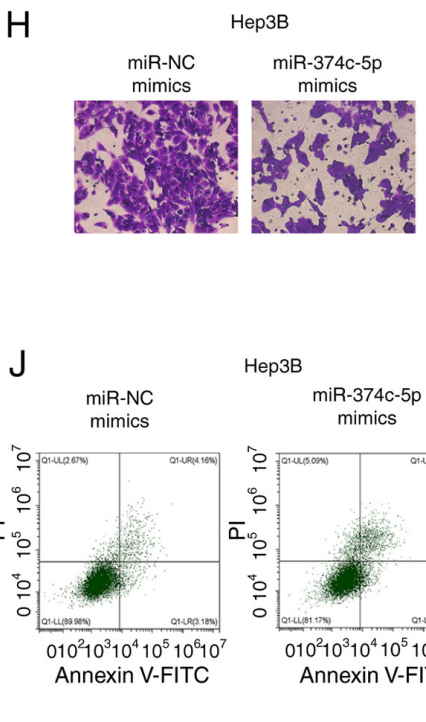
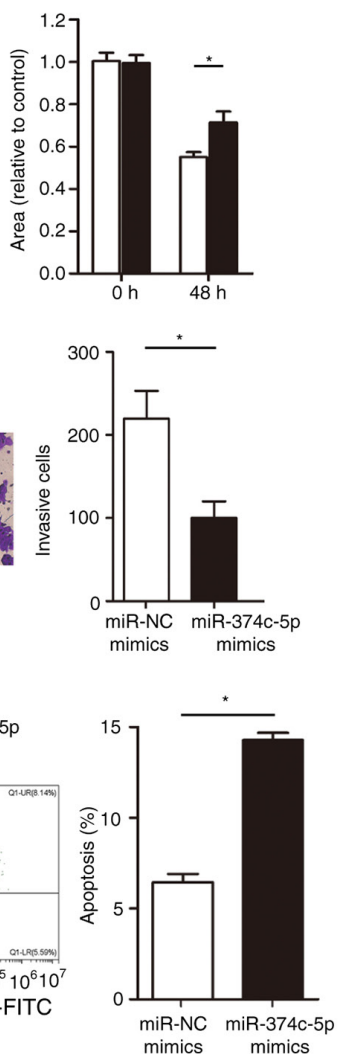

Figure 3. miR-374c-5p inhibits hepatocellular carcinoma cell proliferation, migration and invasion in vitro. (A and B) Cell proliferation ability was determined by Cell Counting Kit-8 assay after miR-374c-5p overexpression in (A) Huh-7 and (B) Hep3B cells. (C and D) Cell proliferation was detected with EdU incorporation assays after miR-374c-5p overexpression in (C) Huh-7 and (D) Hep3B cells (magnification, x200). (E and F) Cell migration ability was determined by wound healing assays after miR-374c-5p overexpression in (E) Huh-7 and (F) Hep3B cells (magnification, $x 100)$. (G and H) The cell invasion ability of (G) Huh-7 and (H) Hep3B cells overexpressing miR-374c-5p was determined by Transwell invasion assays (magnification, $\mathrm{x} 200$ ). (I and J) The cell apoptosis of (I) Huh-7 and (J) Hep3B cells overexpressing miR-374c-5p was determined by flow cytometry. ${ }^{*} \mathrm{P}<0.05$ and ${ }^{* *} \mathrm{P}<0.01$. miR, microRNA. 
A

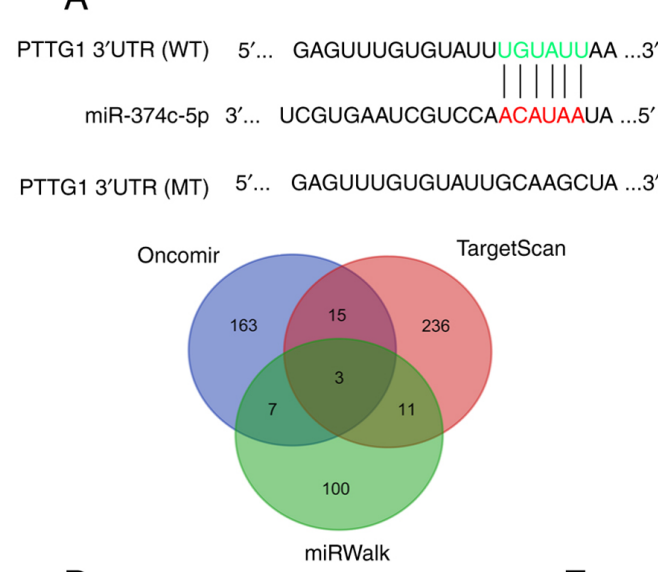

D

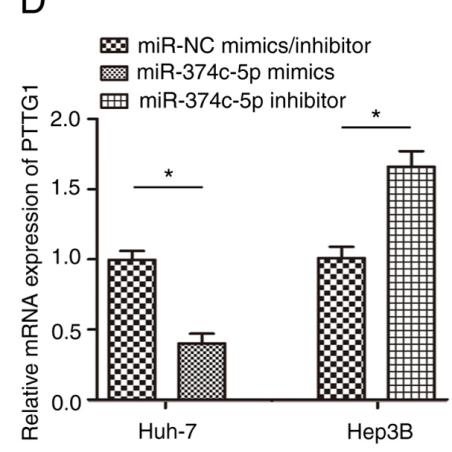

B

$\square$ miR-NC mimics

min-374c-5p mimics

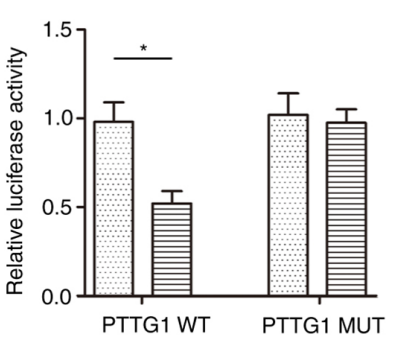

C
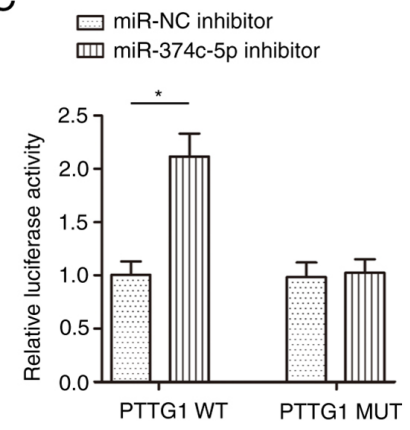

$\mathrm{E}$

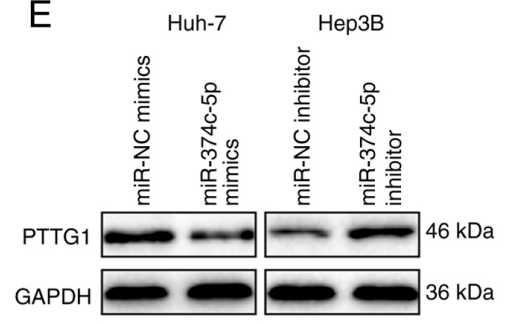

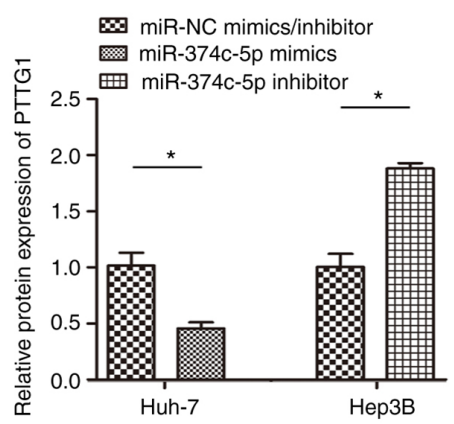

Figure 4. miR-374c-5p directly targets PTTG1. (A) Diagrams reveal putative miR-374c-5p binding sites and corresponding mutant sites in PTTG1. (B and C) The luciferase activity of each combination was assessed. (D) PTTG1 mRNA expression in Huh-7-miR-374c-5p mimics and Huh-7-miR-374c-5p inhibitor cells. (E) PTTG1 protein expression in Huh-7-miR-374c-5p mimics cells and Huh-7-miR-374c-5p inhibitor cells. *P<0.05. miR, microRNA; PTTG1, pituitary tumor-transforming 1 .

tumor proliferation and metastasis. The effect of miR-374c-5p on the prognosis of HCC may involve the expression of gene transcription factors and N6-methyladenosine modification of genes. By regulating the key factors in these signaling pathways, the EMT process that regulates the malignant progression of HCC cells is altered and the invasion of HCC cells is promoted (21-23). Based on the analysis of previous studies and the summary of the present results, it was determined that the molecular mechanism of overexpression of miR-374c-5p inhibiting the occurrence and metastasis of HCC may be similar to that in other tumors, such as regulating the expression of EMT key proteins, the FOXC1/Snail pathway and N6 methyladenosine $(21,23)$. Of course, further experiments are required focusing on the aforementioned molecular mechanism to further verify the effect of miR-374c-5p on the occurrence and metastasis of HCC. In agreement with these data, it was revealed that the expression of miR-374c-5p was lower in HCC than in normal adjacent tissues. Patients with low miR-374c-5p expression had poor prognosis and short survival time. MiR-374c-5p expression was an independent prognostic factor for OS and DSS in HCC. Furthermore, overexpression of miR-374c-5p inhibited HCC cell proliferation, migration and invasion in vitro and in vivo.

EMT is a process in which epithelial cells transform into mesenchymal cells under specific physiological or pathological conditions (24). In previous years, EMT has been demonstrated to play an important role in tumor metastasis. EMT occurs at the initial stage of tumor metastasis and can lead to the loss of the expression of E-cadherin, claudin, occludin and other junction molecules in epithelial cells. It can also destroy cell polarity and increase the expression of lysozymes involved in degradation of the extracellular matrix and basement membrane, such as matrix metalloproteinases, thus destroying the histological barrier to tumor cell invasion. Concurrently, EMT can promote the production of cancer stem cells (CSCs) $(25,26)$. In HCC, cancer-promoting molecules induce EMT by activating the Notch and Wnt signaling pathways upstream of EMT or by regulating the activities of the EMT-related transcription factors ZEB2 and Snail II (27). Concurrently, it was found that EMT can also cause HCC cells to obtain stem cell characteristics, thus promoting the production of HCC CSCs and accelerating the invasion and metastasis of tumor cells (28). In the present study, it was demonstrated that miR-374c-5p directly targeted the 3'-UTR of PTTG1 and regulated the expression of PTTG1. Additionally, miR-374c-5p altered EMT by affecting PTTG1 expression thereby affecting the malignant biological behavior of HCC.

PTTG1 plays an important role in a variety of malignant tumors (29-31). A recent study revealed that PTTG1 acts as a marker of tumor stem cells and regulates tumor stem cells, germline and stem cell-related genes and the malignant progression of ovarian tumors by affecting the self-renewal and epithelial-mesenchymal transformation ability of tumor stem cells (32). In addition, PTTG1 protein expression was found to be significantly higher in colorectal cancer tissues 
A

Huh-7-miR-374c-5p

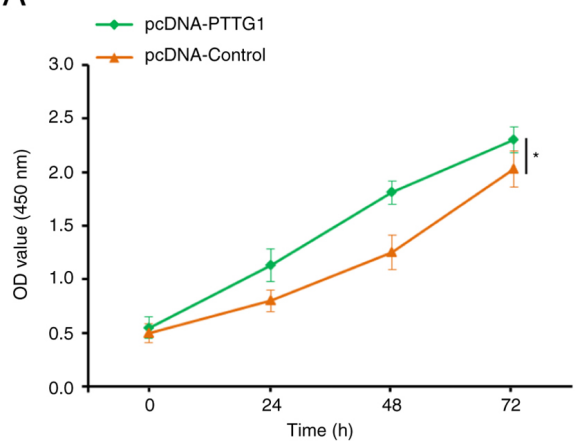

C
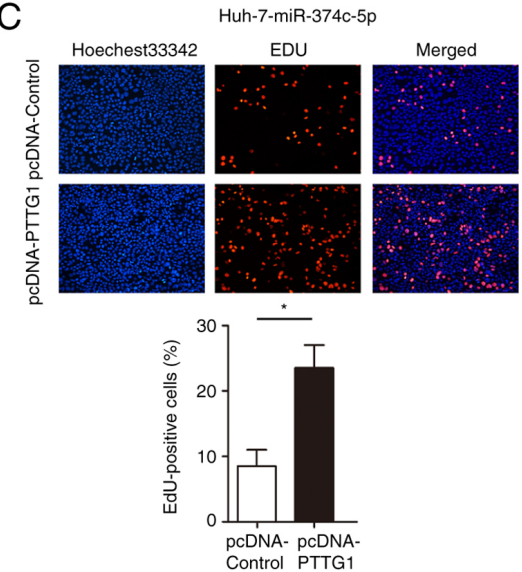

E

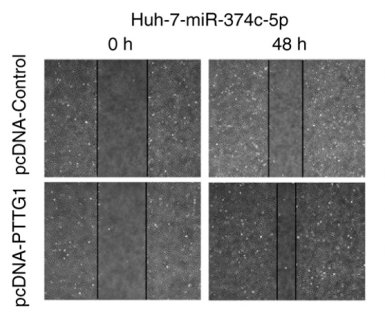

G

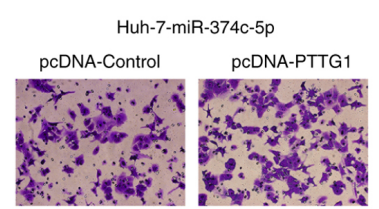

$\square$ pcDNA-Control pcDNA-PTTG1
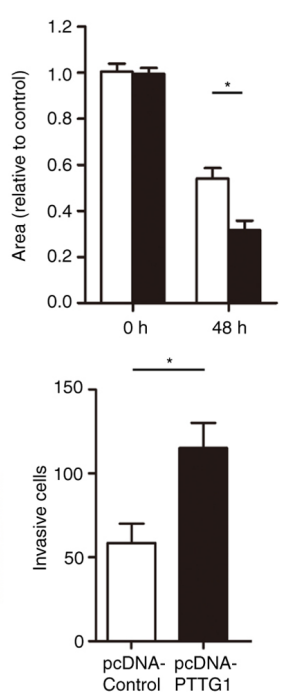

B

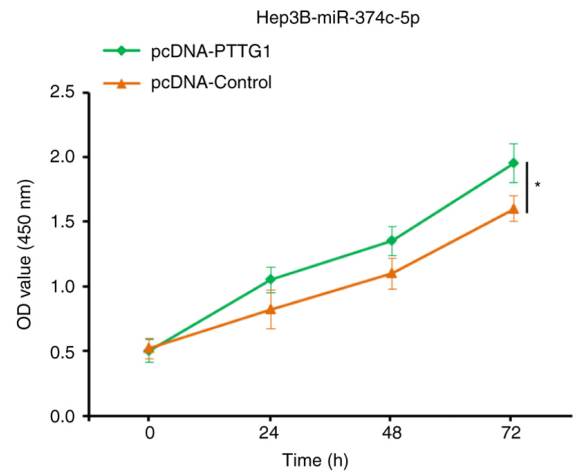

D
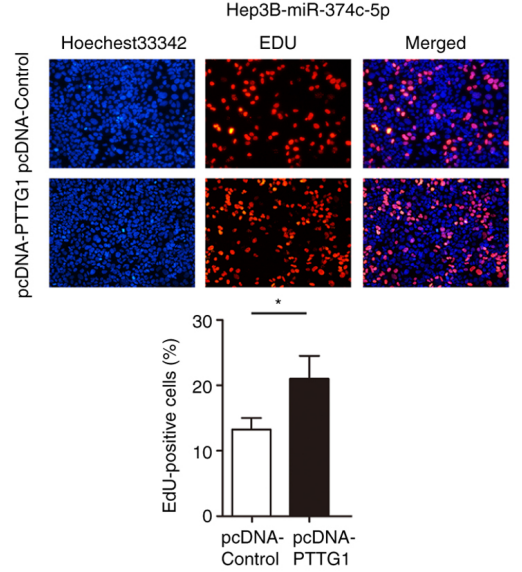

F

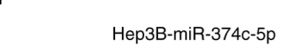

oh $\quad 48 \mathrm{~h}$

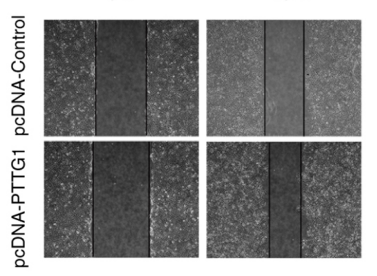

$\mathrm{H}$

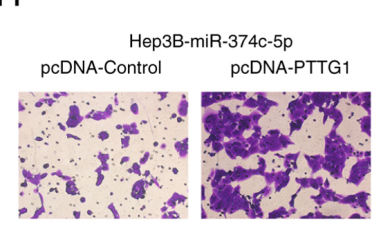

$J$

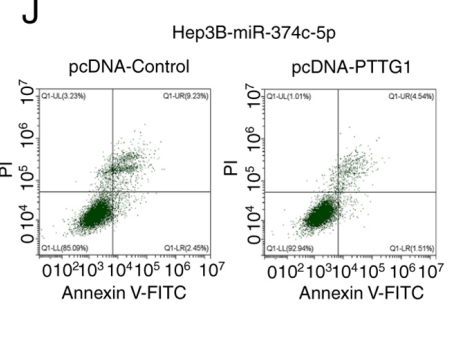

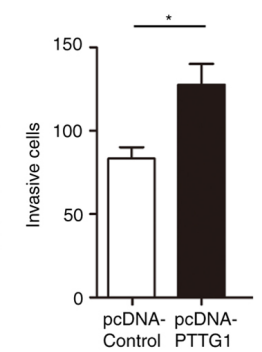

$\square$ pcDNA-Control

\section{pcDNA-PTTG1}
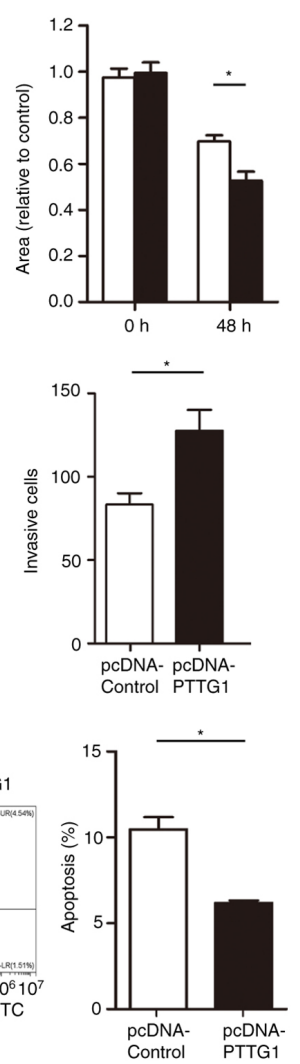

Figure 5. Rescue experiments to confirm that PTTG1 is the functional target of miR-374c-5p in hepatocellular carcinoma proliferation, migration and invasion . (A and B) Cell proliferation ability was determined by Cell Counting Kit-8 assay to examine the effects of PTTG1 during miR-374c-5p overexpression in (A) Huh-7 and (B) Hep3B cells. (C and D) Cell proliferation was detected with EdU to examine the effects of PTTG1 in (C) Huh-7 and (D) Hep3B cells after miR-374c-5p overexpression (magnification, x200). (E and F) A wound healing assay was performed to determine the effects of PTTG1 on (E) Huh-7 and (F) Hep3B cell migration after miR-374c-5p overexpression (magnification, $\mathrm{x} 100$ ). ( $\mathrm{G}$ and $\mathrm{H}$ ) Matrigel invasion assays were performed to determine the effects of PTTG1 on (G) Huh-7 and (H) Hep3B cell invasion after miR-374c-5p overexpression (magnification, x200). (I and J) Flow cytometry was performed to determine the effects of PTTG1 on (I) Huh-7 and (J) Hep3B cell apoptosis after miR-374c-5p overexpression. "P<0.05. PTTG1, pituitary tumor-transforming 1; miR, microRNA. 


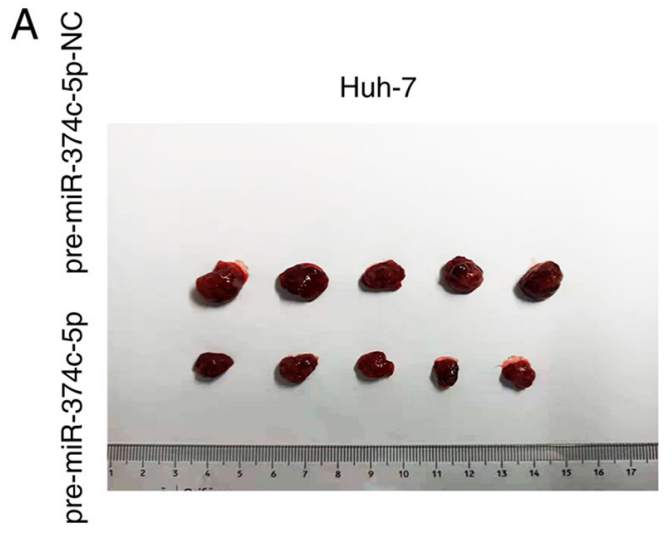

B

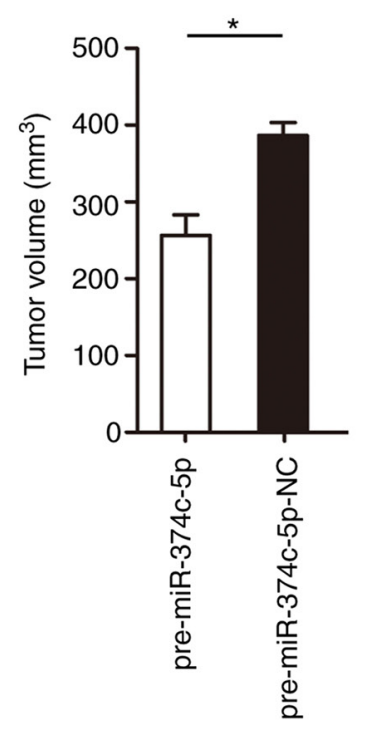

C

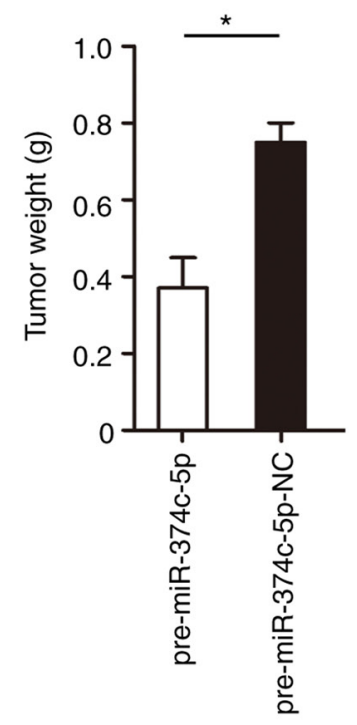

D

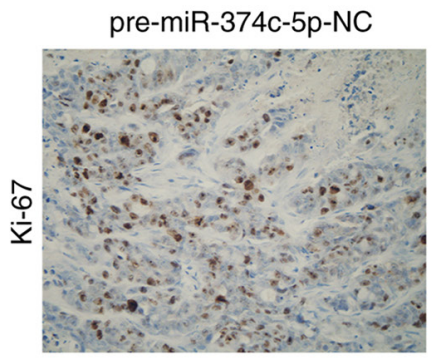

pre-miR-374c-5p

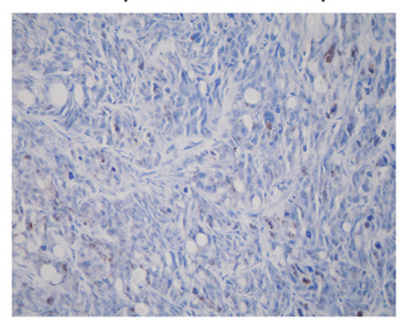

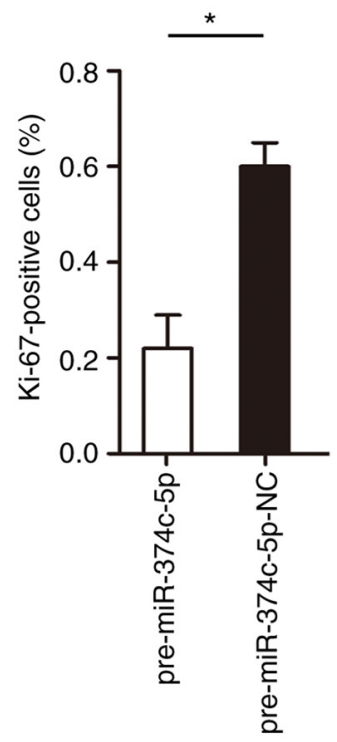

Figure 6. miR-374c-5p inhibits tumor proliferation in a mouse model of hepatocellular carcinoma. (A) Observation of tumor formation after subcutaneous inoculation of Huh-7 cells overexpressing miR-374c-5p into nude mice ( $\mathrm{n}=5$ per group). (B and C) Analysis of the (B) volume and (C) weight of the subcutaneous tumorigenic masses of Huh-7 cells. (D) Representative images of immunohistochemical staining of the Ki-67 antigen in tumors from nude mice (magnification, $\mathrm{x} 200$ ). ${ }^{\mathrm{P}} \mathrm{P}<0.05$. miR, microRNA.

and cell lines (33). The overexpression of PTTG1 was positively correlated with the clinical stage, TNM stage and differentiation of tumors (33). In vitro, knockout of PTTG1 inhibited the growth and metastasis of colorectal cancer (33). Univariate and multivariate analysis showed that PTTG1 overexpression was an independent adverse prognostic factor in patients with colorectal cancer (33). In breast cancer, PTTG1 was associated with a low survival rate and could affect cell cycle arrest in breast cancer cells (34). A recent study revealed that the level of PTTG1 was correlated with that of estrogen and was positively correlated with tamoxifen resistance (34).

In conclusion, the present study provided new evidence that low miR-374c-5p expression promotes HCC growth and metastasis by regulating PTTG1 and can significantly promote EMT. The results suggested that miR-374c-5p can serve as an important target for effective prediction and intervention of malignant progression of HCC. Of course, our research still has certain limitations. In future research, more specimens of clinical patients with HCC will be collected, for further study and analysis of the molecular mechanism of miR-374c-5p in HCC, to provide a scientific and reliable experimental basis for the clinical treatment of HCC.

\section{Acknowledgements}

Not applicable.

\section{Funding}

The present study was supported by Sichuan Provincial Department of Education, (grant no. 16TDD00025), the Popularization and Application Project of Sichuan Health 


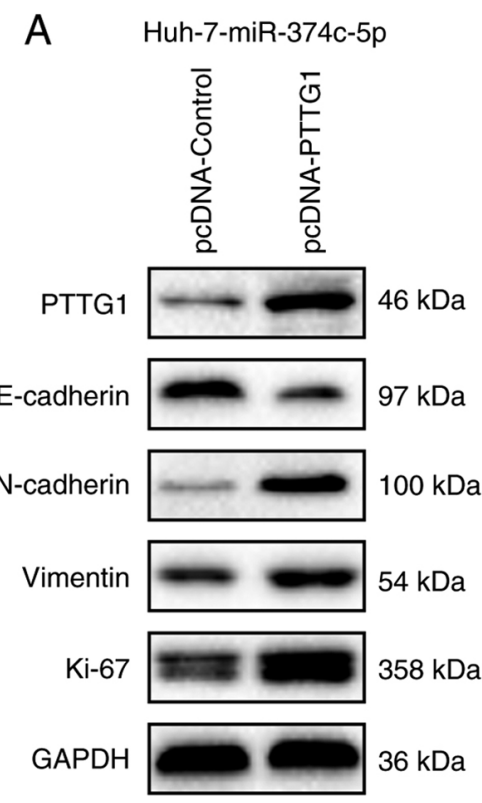

Huh-7-miR-374c-5p

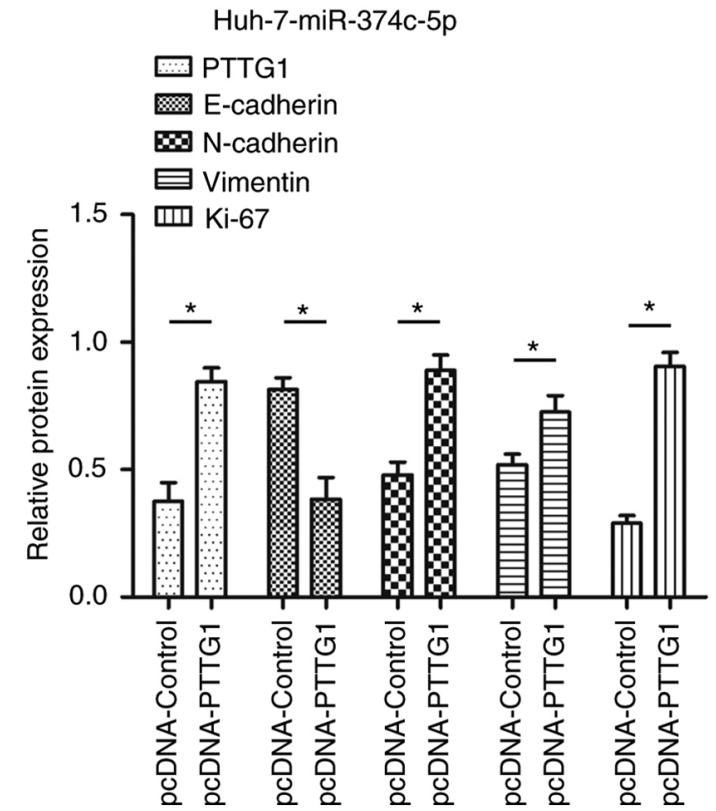

B
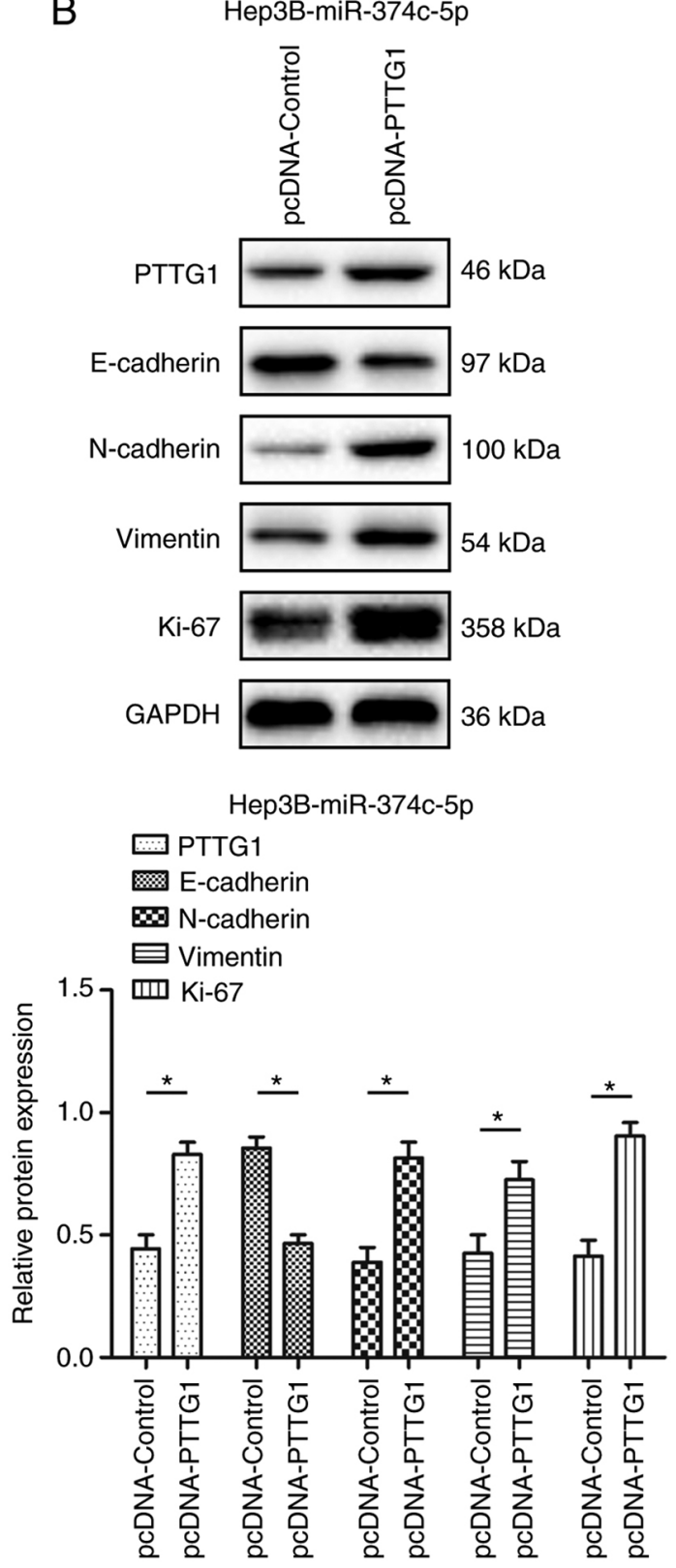

Figure 7. miR-374c-5p affects epithelial-mesenchymal transition in hepatocellular carcinoma through PTTG1. (A and B) Effect of PTTG1 overexpression on the protein expression of PTTG1, N-cadherin, vimentin, E-cadherin and Ki-67 in (A) Huh-7-miR-374c-5p and (B) in Hep3B-miR-374c-5p cells. "P<0.05. miR, microRNA; PTTG1, pituitary tumor-transforming 1.

Commission (grant no. 20PJ149), the Scientific Research Project of Affiliated Hospital of North Sichuan Medical College (grant no. 2020ZD001), the Scientific Research Project of Affiliated Hospital of North Sichuan Medical College (grant no. 2020JC035), the Cooperation Project Between Nanchong City and North Sichuan Medical College (grant nos. 19SXHZ 0290 and 20SXQT0026), the Free Exploring Basic Research Project of Science and Technology of Sichuan province (grant no. 2020YJ0186) and the National Natural Science Foundation of China (grant no. 82003147).

\section{Availability of data and materials}

The datasets used and/or analyzed during the present study are available from the corresponding author on reasonable request.

\section{Authors' contributions}

GY and JL conceived and designed the experiments. YX, GW, WL, TT and JS conducted all the experiments. GY and JL acquired and analyzed the data. GY and JL wrote and revised the manuscript. GY, YX, GW, WL, TT, JS and JL confirm the authenticity of all the raw data. All authors read and approved the final manuscript.

\section{Ethics approval and consent to participate}

The present study was approved (approval no. 2014032) by the Ethics Committee of Affiliated Hospital of North Sichuan Medical College (Nanchong, China). The present study was performed in accordance with the principles outlined in the 
Declaration of Helsinki. All patients provided written informed consent. All animal experiments were approved by the Animal Care Ethics Review Committee of Affiliated Hospital of North Sichuan Medical College, approval no. 20201026.

\section{Patient consent for publication}

Not applicable.

\section{Competing interests}

The authors declare that they have no competing interests.

\section{References}

1. Siegel RL, Miller KD and Jemal A: Cancer statistics, 2020. CA Cancer J Clin 70: 7-30, 2020.

2. McGlynn KA, Petrick JL and El-Serag HB: Epidemiology of hepatocellular carcinoma. Hepatology 73 (Suppl 1): S4-S13, 2021.

3. Llovet JM, Kelley RK, Villanueva A, Singal AG, Pikarsky E, Roayaie S, Lencioni R, Koike K, Zucman-Rossi J and Finn RS: Hepatocellular carcinoma. Nat Rev Dis Primers 7: 6, 2021.

4. Morishita A, Oura K, Tadokoro T, Fujita K, Tani J and Masaki T: MicroRNAs in the pathogenesis of hepatocellular carcinoma: A review. Cancers (Basel) 13: 514, 2021.

5. Bartel DP: MicroRNAs: Target recognition and regulatory functions. Cell 136: 215-233, 2009.

6. Hobert O: Gene regulation by transcription factors and microRNAs. Science 319: 1785-1786, 2008.

7. Bartel DP: MicroRNAs: Genomics, biogenesis, mechanism, and function. Cell 116: 281-297, 2004.

8. Cohen A, Burgos-Aceves MA and Smith Y: Estrogen repression of microRNA as a potential cause of cancer. Biomed Pharmacother 78: 234-238, 2016.

9. Dong LI, Zheng Y, Gao L and Luo X: lncRNA NEAT1 prompts autophagy and apoptosis in MPTP-induced Parkinson's disease by impairing miR-374c-5p. Acta Biochim Biophys Sin (Shanghai) 53: 870-882, 2021.

10. Livak KJ and Schmittgen TD: Analysis of relative gene expression data using real-time quantitative PCR and the 2(-Delta Delta C(T)) method. Methods 25: 402-408, 2001.

11. Fu H, Zhang Y, Chen Y, Chen J and Chen P: CSN1 facilitates proliferation and migration of hepatocellular carcinoma cells by upregulating cyclin A2 expression. Mol Med Rep 23: 46, 2021.

12. Mullard A: Addressing cancer's grand challenges. Nat Rev Drug Discov 19: 825-826, 2020.

13. Puik JR, Meijer LL, Le Large TY, Prado MM, Frampton AE, Kazemier $\mathrm{G}$ and Giovannetti E: miRNA profiling for diagnosis, prognosis and stratification of cancer treatment in cholangiocarcinoma. Pharmacogenomics 18: 1343-1358, 2017.

14. Esquela-Kerscher A and Slack FJ: Oncomirs-microRNAs with a role in cancer. Nat Rev Cancer 6: 259-269, 2006.

15. Zhang M, Matyunina LV, Walker LD, Chen W, Xiao H, Benigno BB, Wu R and McDonald JF: Evidence for the importance of post-transcriptional regulatory changes in ovarian cancer progression and the contribution of miRNAs. Sci Rep 7: $8171,2017$.

16. Perron MP and Provost P: Protein interactions and complexes in human microRNA biogenesis and function. Front Biosci 13: 2537-2547, 2008.

17. Oliveto S, Mancino M, Manfrini $\mathrm{N}$ and Biffo S: Role of microRNAs in translation regulation and cancer. World $J$ Biol Chem 8: 45-56, 2017.
18. He C, Li Z, Chen P, Huang H, Hurst LD and Chen J: Young intragenic miRNAs are less coexpressed with host genes than old ones: Implications of miRNA-host gene coevolution. Nucleic Acids Res 40: 4002-4012, 2012.

19. Gao X, Qiao Y, Han D, Zhang Y and Ma N: Enemy or partner: Relationship between intronic micrornas and their host genes. IUBMB Life 64: 835-840, 2012.

20. Hinske LC, Galante PA, Kuo WP and Ohno-Machado L: A potential role for intragenic miRNAs on their hosts' interactome. BMC Genomics 11: 533, 2010.

21. Huang Y, Huang H, Li M, Zhang X, Liu Y and Wang Y: MicroRNA-374c-5p regulates the invasion and migration of cervical cancer by acting on the Foxc1/snail pathway. Biomed Pharmacother 94: 1038-1047, 2017.

22. Hao S, Tian W, Chen Y, Wang L, Jiang Y, Gao B and Luo D: MicroRNA-374c-5p inhibits the development of breast cancer through TATA-box binding protein associated factor 7-mediated transcriptional regulation of DEP domain containing 1. J Cell Biochem 120: 15360-15368, 2019.

23. Yue Y, Deng P, Xiao H, Tan M, Wang H, Tian L, Xie J, Chen M, Luo Y, Wang L, et al: N6-methyladenosine-mediated downregulation of miR-374c-5p promotes cadmium-induced cell proliferation and metastasis by targeting GRM3 in breast cancer cells. Ecotoxicol Environ Saf 229: 113085, 2022.

24. Nieto MA, Huang RY, Jackson RA and Thiery JP: EMT: 2016. Cell 166: 21-45, 2016.

25. Pastushenko I and Blanpain C: EMT transition states during tumor progression and metastasis. Trends Cell Biol 29: 212-226, 2019.

26. Jayachandran A, Dhungel B and Steel JC: Epithelial-tomesenchymal plasticity of cancer stem cells: Therapeutic targets in hepatocellular carcinoma. J Hematol Oncol 9: 74, 2016.

27. Giannelli G, Koudelkova P, Dituri F and Mikulits W: Role of epithelial to mesenchymal transition in hepatocellular carcinoma. J Hepatol 65: 798-808, 2016.

28. Georgakopoulos-Soares I, Chartoumpekis DV, Kyriazopoulou V and Zaravinos A: EMT factors and metabolic pathways in cancer. Front Oncol 10: 499, 2020.

29. Guo XC, Li L, Gao ZH, Zhou HW, Li J and Wang QQ: The long non-coding RNA PTTG3P promotes growth and metastasis of cervical cancer through PTTG1. Aging (Albany NY) 11: 1333-1341, 2019.

30. Horning AM, Wang Y, Lin CK, Louie AD, Jadhav RR, Hung CN, Wang CM, Lin CL, Kirma NB, Liss MA, et al: Single-Cell RNA-seq reveals a subpopulation of prostate cancer cells with enhanced cell-cycle-related transcription and attenuated androgen response. Cancer Res 78: 853-864, 2018.

31. Qiu M, Li G, Wang P, Li X, Lai F, Luo R, Liu B and Lin J: aarF domain containing kinase 5 gene promotes invasion and migration of lung cancer cells through ADCK5-SOX9-PTTG1 pathway. Exp Cell Res 392: 112002, 2020.

32. Parte S, Virant-Klun I, Patankar M, Batra SK, Straughn A and Kakar SS: PTTG1: A unique regulator of stem/cancer stem cells in the ovary and ovarian cancer. Stem Cell Rev Rep 15: 866-879, 2019.

33. Ren Q and Jin B: The clinical value and biological function of PTTG1 in colorectal cancer. Biomed Pharmacother 89: 108-115, 2017.

34. Meng C, Zou Y, Hong W, Bao C and Jia X: Estrogen-regulated PTTG1 promotes breast cancer progression by regulating cyclin kinase expression. Mol Med 26: 33, 2020.

This work is licensed under a Creative Commons Attribution-NonCommercial-NoDerivatives 4.0 International (CC BY-NC-ND 4.0) License. 